\title{
Realisation of Pressure Sensor using one Dimensional Indium Arsenide (InAs) Based Photonic Waveguide in 3 Communication Windows
}

CHANDRA SEKHAR MISHRA ( $\nabla$ csmisra2010@gmail.com )

Gandhi Institute For Technological Advancement https://orcid.org/0000-0003-0661-7485

Manas Ranjan Nayak

BPUT: Biju Patnaik University of Technology

Rajesh Arunachalam

CVR College Of Engineering

Gopinath Palai

Gandhi Institute for Technological Advancement

Research Article

Keywords: Pressure, indium arsenide, PWE, Reflection

Posted Date: April 19th, 2021

DOl: https://doi.org/10.21203/rs.3.rs-393610/v1

License: (c) (i) This work is licensed under a Creative Commons Attribution 4.0 International License.

Read Full License 


\title{
Realisation of pressure sensor using one dimensional indium arsenide (InAs) based photonic waveguide in 3-communication windows
}

\author{
C.S.Mishra ${ }^{1,2}$, M.R.Nayak ${ }^{3}$, Rajesh Arunachalam ${ }^{4}$, G.Palai ${ }^{1 *}$
}

1. Department of Electronics and Communication Engineering, Gandhi institute for Technological Advancement, Bhubaneswar, India

2. Biju Patnaik University of Technology, Odisha, Rourkela, India

3. Department of Electrical Engineering, Centre for Advanced Post Graduate Studies, Biju Patnaik University and Technology, Odisha, Rourkela, India

4. Department of Electronics and Communication Engineering, CVR College of Engineering, Hyderabad, India

*Corresponding author: gpalai28@gmail.com

\begin{abstract}
Indium arsenide (InAs) based one dimensional photonic crystal waveguide is cautiously considered in three optical communication windows. Here, the emerging transmitted signal from one dimensional photonic structure is determined with the consideration of five types of losses (diffraction loss, reflection loss, absorption loss, propagation loss, polarisation loss). Further, the transmitted signal is obtained with respect to pressure, which ranges from $0 \mathrm{GPa}$ to $5 \mathrm{GPa}$ for different lattice constant of photonic structure $(100 \mathrm{~nm}, 120 \mathrm{~nm}, 140 \mathrm{~nm})$. Simulation upshots revealed that indium arsenide semiconductor based photonic waveguide shows an excellent outcome for pressure sensor in the three optical windows as well as different waveguide lengths.
\end{abstract}

Keywords: - Pressure, indium arsenide, PWE, Reflection

\section{Introduction}

In recent times, group of III-IV compound semiconductors have exhibited an outstanding performance in the design of optoelectronic devices for their unique optical characteristics with respect to low noise, high stability, and high breakdown voltage [1]. Moreover, Indium Arsenide (InAs) is an excellent material, which shows little unusual direct band gap properties that become widely applied in the construction of different efficient photonic devices. For example, photovoltaic infrared detector, photochemical sensors, fast transistors, and solar cells so on [2]. Moreover, an optical characteristics of such photonic material is useful for band gap investigation [3]. As far as a literature review of the photonic structure is concerned, a good number of research papers are previously published on semiconductor waveguides [4]. Aside this, a few number of articles are found for sensing applications by photonic waveguide structure [5-8]. For example; reference[5] investigates the sucrose concentration in metamaterial by deploying plane wave expansion technique, while in the reference [6], authors describe the investigation of polymer based optical waveguide 
pertaining to the temperature. Again in the reference [7-8], authors point out various losses in photonic waveguide with respect to the variety of sensing parameters such as porosity, temperature, concentration etc for realising competent photonic integrated circuit. Experimental demonstration of one dimensional strain sensor and its application have been discussed [9]. Polymer based $1 \mathrm{D}$ photonic crystal have been investigated in the reference [10]. Even though reference [6-10] provides the notion on different sensor, reference [11-18] explains the different pressure sensors and their outcomes, which is indicated in the tabular form (Table 1)

\begin{tabular}{|c|c|c|}
\hline Reference & Outcomes of the work & Limitations \\
\hline [11] & $\begin{array}{l}\text { GaN semiconductor } \\
\text { waveguide is discussed for } \\
\text { effect of pressure and } \\
\text { temperature at } 700 \mathrm{~nm}\end{array}$ & $\begin{array}{l}\text { Here the absorption and } \\
\text { reflections losses are } \\
\text { considered only. } \\
\text { No consideration of } \\
\text { polarization, diffraction and } \\
\text { propagation during } \\
\text { computation. }\end{array}$ \\
\hline [12] & $\begin{array}{l}\text { The mechanical tunable filter } \\
\text { and reflector is realized } \\
\text { through one dimensional } \\
\text { photonic crystal via elasto- } \\
\text { optical theory, plane wave } \\
\text { expansion and perturbation } \\
\text { methods. The operational } \\
\text { signal varies from } 2 \mu \mathrm{m} \text { to } 20 \\
\mu \mathrm{m} \text {. }\end{array}$ & $\begin{array}{l}\text { Neither consideration of } \\
\text { different losses nor the } \\
\text { inclusion of three } \\
\text { communication windows. }\end{array}$ \\
\hline [13] & $\begin{array}{l}\text { Authors focus on the relation } \\
\text { between pressure and stop } \\
\text { wavelength using bandgap } \\
\text { analysis. }\end{array}$ & $\begin{array}{l}\text { Neither consideration of } \\
\text { different losses nor the } \\
\text { inclusion of three } \\
\text { communication windows. }\end{array}$ \\
\hline [14] & $\begin{array}{l}\text { In this research, authors } \\
\text { report on the analysis of } \\
\text { optical properties through } \\
\text { shifting vapour pressure. }\end{array}$ & $\begin{array}{l}\text { Here the reflections losses } \\
\text { considered only. } \\
\text { No consideration of } \\
\text { absorption, polarization, }\end{array}$ \\
\hline
\end{tabular}




\begin{tabular}{|c|c|c|}
\hline & & $\begin{array}{l}\text { diffraction and propagation } \\
\text { during computation. } \\
\text { Exclusion of optical window } \\
\text { signals. }\end{array}$ \\
\hline$[15]$ & $\begin{array}{l}\text { In this research authors } \\
\text { design a micro sensor using } \\
\text { defect photonic crystal } \\
\text { waveguide at the signal of } \\
1550 \mathrm{~nm} \text {. }\end{array}$ & $\begin{array}{l}\text { Here authors use } 1550 \mathrm{~nm} \\
\text { signal only. No consideration } \\
\text { of first and second optical } \\
\text { communication windows. }\end{array}$ \\
\hline [16] & $\begin{array}{l}\text { In this work, authors design a } \\
\text { defect based one dimensional } \\
\text { photonic crystal structure to } \\
\text { realize hydrostatic pressure } \\
\text { and temperature using the } \\
\text { signal of } 1300 \mathrm{~nm} \text {. }\end{array}$ & $\begin{array}{l}\text { Only transmission and } \\
\text { sensibility of structure is } \\
\text { discussed. No observation of } \\
\text { first and third optical } \\
\text { communication windows. }\end{array}$ \\
\hline [17] & $\begin{array}{l}\text { In this work, defect based one } \\
\text { dimensional superconductor } \\
\text { photonic structure is } \\
\text { considered to envisage } \\
\text { temperature and hydrostatic } \\
\text { pressure sensor using transfer } \\
\text { matrix method. }\end{array}$ & $\begin{array}{l}\text { No indication of optical } \\
\text { communication windows. } \\
\text { Only reflection loss is } \\
\text { focused. }\end{array}$ \\
\hline$[18]$ & $\begin{array}{l}\text { Here authors use one } \\
\text { dimensional semiconductor- } \\
\text { superconductor photonic } \\
\text { crystal structure to investigate } \\
\text { the temperature and pressure } \\
\text { sensor at the signal of } 17 \mathrm{THz} \\
\text { only. }\end{array}$ & $\begin{array}{l}\text { No indication of any optical } \\
\text { communication windows. } \\
\text { Exclusion of diffraction of } \\
\text { polarization and propagation } \\
\text { loss. }\end{array}$ \\
\hline Present work & $\begin{array}{l}\text { This paper focuses on several } \\
\text { losses(diffraction, reflection, } \\
\text { absorption, } \\
\text { polarization) }\end{array}$ & \\
\hline
\end{tabular}


Even though several type works relating to pressure sensor have been done, the present paper has merits in terms of different type of losses at three different communication windows. For example; the present investigation focuses on the several types of losses such as absorption, reflection, scattering, diffraction, polarization, which are occurred in the photonic structures. Aside this, such investigation is made at three optical communication windows to fetch the pressure on the photonic structures. The applied pressure plays a vital role in the photonic crystal waveguide for managing the various optical properties of compound semiconductor material. To compute the transmitted intensity of indium arsenide based waveguide structure, the different type of losses play a crucial role corresponding to different pressure and lattice spacing in the three optical communication windows, which can be used a pressure sensor. Here, three optical communication windows have been considered or each pressure. Focusing on the optical windows, we know that window considers from $800-900 \mathrm{~nm}$ with signal loss of $4 \mathrm{~dB} / \mathrm{km}$. The second optical window is occupied at $1310 \mathrm{~nm}$ also known as O-band, which signal loss occurs at $0.5 \mathrm{~dB} / \mathrm{km}$. The third optical window is considered at $1550 \mathrm{~nm}$ also known as C-band, which provides the loss of $0.2 \mathrm{~dB} / \mathrm{km}$ and the $1550 \mathrm{~nm}$ wavelength is chosen for long distance applications due to the lowest loss accessible at this wavelength than other.

\section{Structure Analysis}

We have proposed a 1-D semiconductor (InAs) based waveguide photonic structure to realise the pressure (from $0 \mathrm{GPa}$ to $5 \mathrm{GPa}$ ) sensor with respect to the output transmitted intensity, which is indicated in figure $1(\mathrm{a})$. 

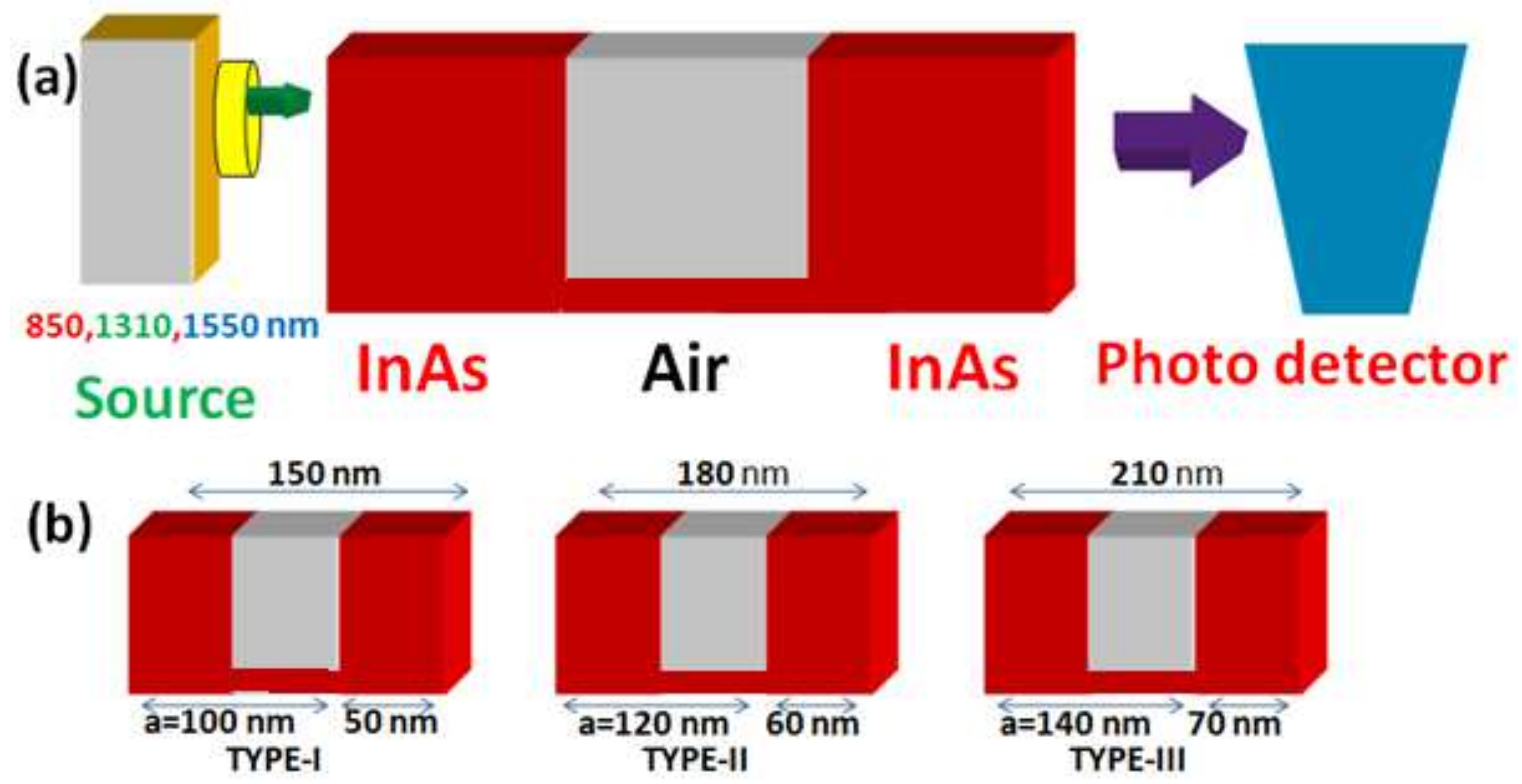

Figure 1 :(a) proposed InAs 1-D waveguide structure b) 1-D InAs based photonic structure with different waveguide lengths.

The aforesaid photonic waveguides consist of three layers, having a width of each $50 \mathrm{~nm}$, and the second layer is enclosed air. Here substrate material is taken as InAs and a definite thickness of InAs have been removed. The etched portion fills with the air. The key reason for choosing the above width is to obtain different losses (diffraction loss, reflection loss, absorption loss, propagation loss, polarisation loss) which play a major role for the realization of optical sensing in the photonic waveguide structure. Refractive index deviation is found under different pressure from reference [19], which is reported in table 2 .

Table2: Refractive index of InAs for different pressures

\begin{tabular}{|l|r|r|r|r|r|r|r|r|r|r|r|}
\hline Pressure(GPa) & 0 & 0.5 & 1 & 1.5 & 2 & 2.5 & 3 & 3.5 & 4 & 4.5 & 5 \\
\hline $\mathrm{Ri}$ & 4.62 & 4.48 & 4.35 & 4.26 & 4.17 & 4.08 & 4 & 3.94 & 3.88 & 3.84 & 3.76 \\
\hline
\end{tabular}

Here we compared different waveguide lengths for 3 optical communication windows such as 850 $\mathrm{nm}, 1310 \mathrm{~nm}$ and $1550 \mathrm{~nm}$. For example, there are 3 different types waveguide has been considered, which are represented in figure 1(b). It is observed that the waveguide length of InAs $150 \mathrm{~nm}, 180 \mathrm{~nm}$ and $210 \mathrm{~nm}$ for type-I, type-II and type-III respectively. The width of each layer is chosen as $50 \mathrm{~nm}$, $60 \mathrm{~nm}$ and $70 \mathrm{~nm}$ for type-I, type-II and type-III respectively. Further, we observed (from figure-1) that the signal of $850 \mathrm{~nm}, 1310 \mathrm{~nm}$ and $1550 \mathrm{~nm}$ impinges the aforementioned photonic structure separately, subsequently incident signal attenuates because of suffering from different losses such as diffraction loss, reflection loss, absorption loss, propagation loss, polarisation loss etc. After suffering from these losses, the signals collected at the output end, where transmitted intensity is computed with the term of photo detector.

As far as practical feasibility of proposed photonic crystal is concerned, reference [20-25] states the different research with respect to the experimental work. For example; reference [20] provides an idea 
of fabrication of titanium metal oxide based one dimensional photonic structure for calorimetric sensor which measures the volatile organic compound and relative humidity. Similarly in the reference [21], authors fabricate one dimensional periodic nanostructure to investigate the various chemical components. Further fabrication of erbium chloride silicate nanowire based one dimensional photonic crystal is discussed in the reference [22]. In the reference [23], authors characterize one dimensional multilayer structure through atomic force microscopy, ellipsometry and visible-near IR spectroscopy. Aside these, reference [24] shows a method to fabricate porous silicon (pSi) based onedimensional photonic crystal by photoacoustics for radiometry application. Again in the reference [25], authors use physical vapor oblique angle deposition technique to design $\mathrm{TiO} 2-\mathrm{SiO} 2$ based one dimensional photonic crystal structure. Since the present structure is similar to the reference [20-25], the InAs based one dimensional could be fabricated for computing the amount of the pressure.

\section{Mathematical equations}

The current research paper treats with different type losses to compute the amount of pressure impacted on the photonic structure. These losses are diffraction loss, reflection loss, absorption loss, propagation loss and polarisation loss, which is discussed here.

The equation for absorption loss can be represented in terms of absorption coefficient as

$A=e^{-(2 t 1 \beta 1+\mathrm{t} 2 \beta 2)}$

Where, $\beta 1, \beta 2$, $\mathrm{t} 1$ and $\mathrm{t} 2$ denote the absorption coefficient of odd, even layer, the thickness of odd and even layer InAs photonic structure respectively.

In the same way, the reflectance is calculated with the help of Helmholtz equation, which is represented by

$\frac{d^{2} E_{z}}{d x^{2}}+\frac{\omega^{2}}{c^{2}} E_{z}=0$

The result of the equation is

$E_{z}(x, t)=E_{0} e^{i(k \cdot x-\omega t)}$

Moreover, the electric field intensity is calculated through proper boundary condition. Ultimately the reflectance would be

$\operatorname{Ref}=1-\left|E_{z}\right|^{2}$

the diffraction loss is articulated as

$\mathrm{L}_{\mathrm{dif}}=\sin ^{2}\left(\frac{\pi \mathrm{nd}}{\lambda}\right)$ 
Where $\mathrm{n}, \mathrm{d}$ and $\lambda$ denotes the refractive index of material, which varies with pressure, the total thickness of the proposed one dimensional structure, and incident wavelength respectively

Again the polarisation loss is written as

$\mathrm{L}_{\text {pol }}=\frac{\mathrm{N}_{1}}{\mathrm{~N}_{1}+\frac{2 \mathrm{n}}{\mathrm{n}^{2}-1}}$

$\mathrm{N}_{1}$ be the total number of layers in the structures.

Apart from these losses, the equation (6) represents the propagation loss as

$L_{\text {pro }}=e^{\frac{-4 \pi n a}{\lambda}}$

Where $\lambda, \mathrm{n}$ and a are the input wavelength, refractive index, and the lattice constant respectively.

At last, the transmitted intensity can be determined relating to the different losses as

Transmitted intensity $\left(\mathrm{T}_{\mathrm{r}}\right)=$ Transmitted efficiency $\left(\mathrm{T}_{\text {eff }}\right) \times \operatorname{Input}$ signal $\left(\mathrm{I}_{\mathrm{i}}\right)$

Where transmitted efficiency $\left(\mathrm{T}_{\text {eff }}\right)=(1-\mathrm{A}) \times(1-\mathrm{R}) \times\left(1-\mathrm{L}_{\mathrm{dif}}\right) \times\left(1-\mathrm{L}_{\mathrm{pro}}\right) \times\left(1-\mathrm{L}_{\mathrm{pol}}\right)$

Where $\mathrm{A}, \mathrm{R}, \mathrm{L}_{\mathrm{dif}}, \mathrm{L}_{\mathrm{pro}}, \mathrm{L}_{\mathrm{pol}}$ are absorption, reflection, diffraction, propagation, and polarisation losses respectively.

\section{Results Discussions}

From equation (8) and (9), it is found that transmitted intensity depends on the various losses with respect to three optical windows.

\subsection{Absorption loss}

The absorbance relies on both absorption coefficient and thickness of even and odd layer of 1D InAs based photonic structure. The absorption coefficient of indium arsenide material is found from the literature pertaining to all three communication windows. Putting the values in equation (4), it is found the zero loss with the different waveguide lengths as well as 3 optical windows.

\subsection{Reflection loss}

The reflectance loss of indium arsenide based one dimensional photonic structure with respect to pressure (0 GPa-5 GPa) is computed with help of PWE for different waveguide lengths, input wavelength for the $850 \mathrm{~nm}, 1310 \mathrm{~nm}$ and $1550 \mathrm{~nm}$. Simulation is executed to get reflectance for each type of waveguides and different wavelengths. Although simulations of different waveguide lengths and all input signals are performed for pressure ranges from $0 \mathrm{GPa}$ to $5 \mathrm{GPa}$, the reflectance curve for length of the $150 \mathrm{~nm}$ (a lattice spacing $100 \mathrm{~nm}$ ) of $0 \mathrm{GPa}$ appears in figure 2. In the figure 2, reflectance (Arbi Unit) and wavelength (nm) is taken along vertical and horizontal axis respectively. 
Here, the reflectance of indium arsenide photonic waveguide is 0.9494 for $0 \mathrm{GPa}$ at the signal of 850 $\mathrm{nm}$, which is shown in figure 2 .

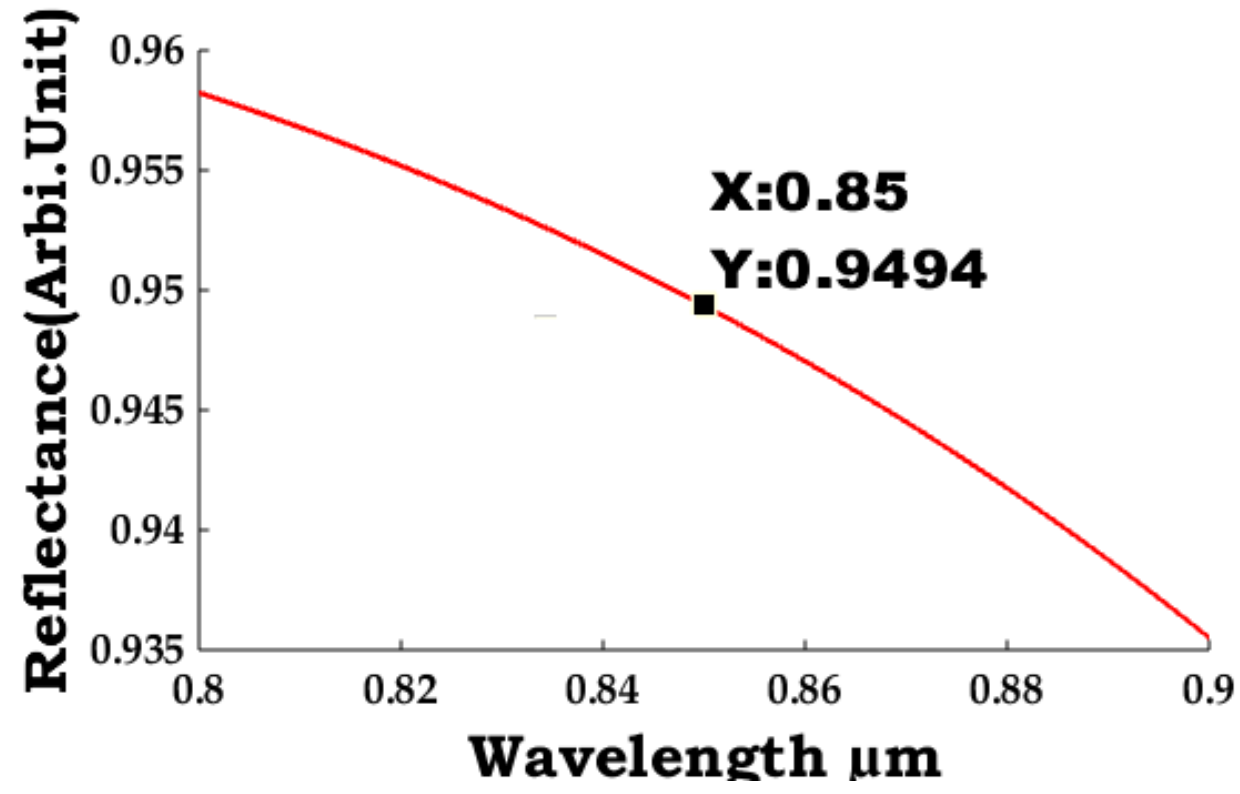

Figure 2: reflectance curve InAs of waveguide length $150 \mathrm{~nm}$ at input signal $850 \mathrm{~nm}$

Similarly, we have computed the reflectance values for different lengths of the photonic structure $(\mathrm{t}=50 \mathrm{~nm}, 60 \mathrm{~nm}$ and $70 \mathrm{~nm})$ corresponding to the three optical communication windows. The pictorial illustration of reflectance losses for all waveguide lengths, all pressure range and different wavelengths are demonstrated in figure 3.

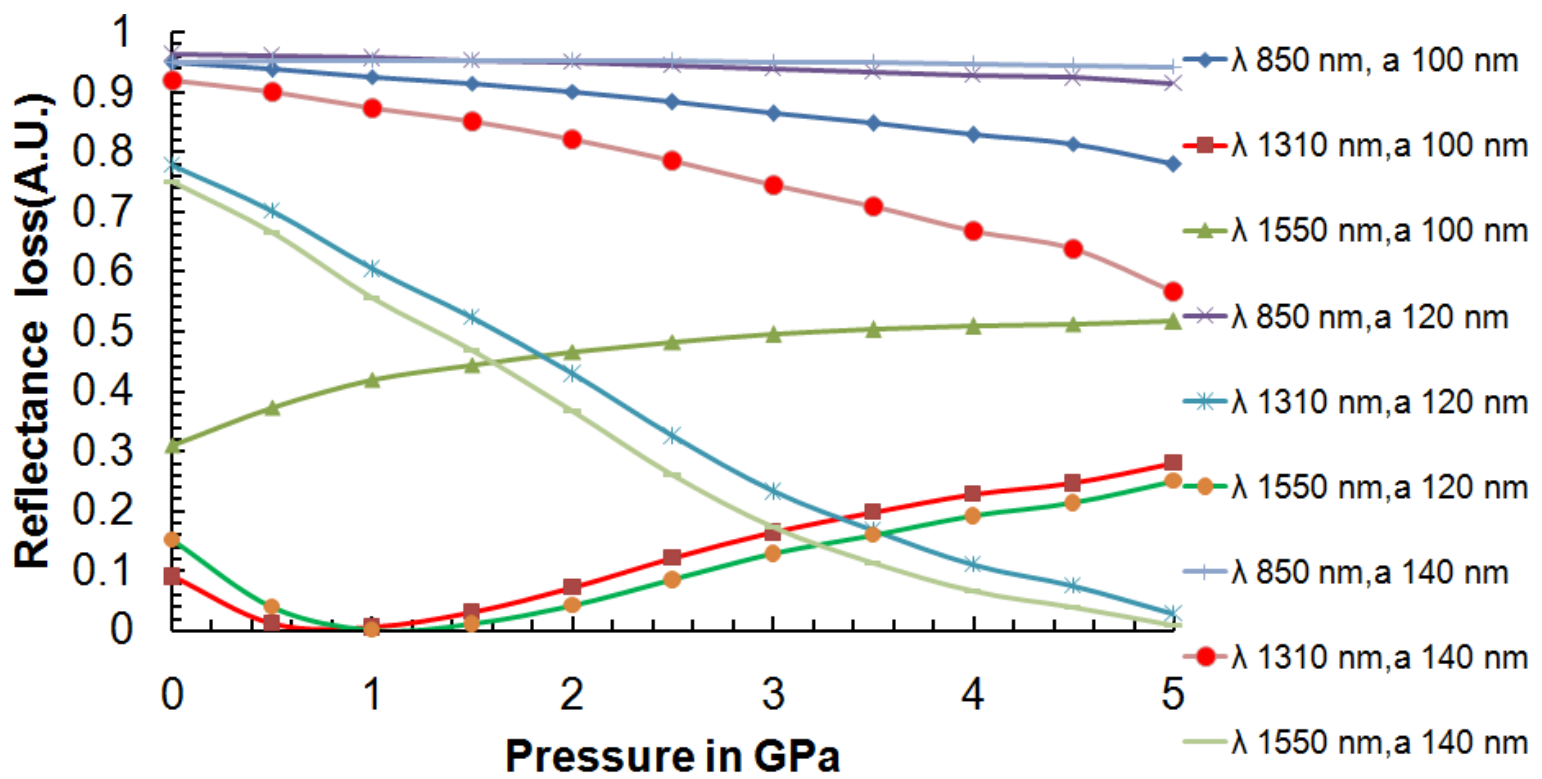

Figure 3: Reflectance graph of InAs waveguide length $150 \mathrm{~nm}$ at input signal $850 \mathrm{~nm}$

The pressure is selected in $\mathrm{x}$ axis and reflectance is taken along y axis in figure 3 . From figure 3 it is represented that reflectance increases linearly at both signal 1310 and $1550 \mathrm{~nm}$, but at the signal of $850 \mathrm{~nm}$, reflectance decreases linearly with the increase of pressure for all waveguide lengths (150 $\mathrm{nm}, 180 \mathrm{~nm}, 210 \mathrm{~nm})$. For example; reflectance of waveguide length of $150 \mathrm{~nm}$ increases from 
0.08972 to 0.2801 and from 0.3094 to 0.517 for wavelength $1310 \mathrm{~nm}$ and $1550 \mathrm{~nm}$ respectively. But the reflectance of waveguide length $150 \mathrm{~nm}$ decreases from 0.9494 to 0.7797 for the signal of $850 \mathrm{~nm}$. Similarly, the reflectance for the waveguide length $180 \mathrm{~nm}$ decreases from 0.9647 to 0.9156 and from 0.7782 to 0.02789 for wavelength $850 \mathrm{~nm}$ and $1310 \mathrm{~nm}$ respectively. But the reflectance corresponding to the waveguide length $180 \mathrm{~nm}$ increases from 0.1507 to 0.2498 for the signal of 1550 $\mathrm{nm}$. Further, the reflectance of waveguide length $210 \mathrm{~nm}$ decreases from 0.9501 to 0.9425 , from 0.9214 to 0.5684 and from 0.7503 to 0.008672 for wavelength $850 \mathrm{~nm}, 1310$ and $1550 \mathrm{~nm}$ respectively.

\subsection{Polarisation and diffraction}

Polarisation and diffraction is calculated for each waveguide length of $150 \mathrm{~nm}, 180 \mathrm{~nm}, 210 \mathrm{~nm}$ and at all the wavelengths $(850 \mathrm{~nm}, 1310 \mathrm{~nm}$ and $1550 \mathrm{~nm})$ of indium arsenide waveguide photonic structure with the help of equations (5) and (6) respectively, the outcomes is graphically represented in figure 4.

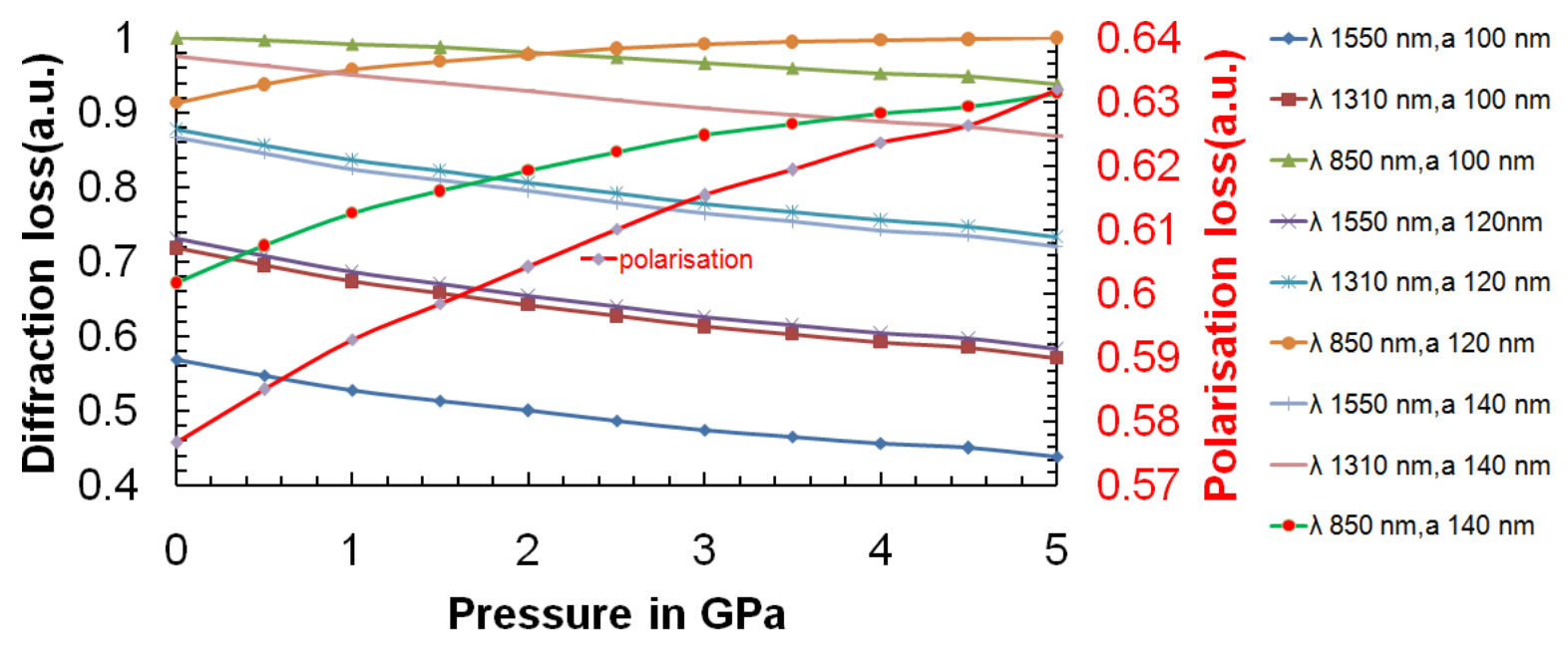

Figure 4: polarisation and diffraction vs pressure 1-D InAs photonic waveguide

Polarisation and diffraction are chosen secondary and primary y axes, where pressure is selected xaxes. From this figure, it is observed that polarisation efficiency increases linearly from 0.5767 to 0.632 with respect to the increment of pressure $(0 \mathrm{GPa}-5 \mathrm{GPa})$, which is clearly depicted in figure 4.Morever, the diffraction efficiency of signal $850 \mathrm{~nm}$ increases from 0.9134 to 0.9998 and 0.6716 to 0.9255 for waveguide length $180 \mathrm{~nm}$ and $210 \mathrm{~nm}$ respectively. However all other cases (including waveguide length and wavelengths) it decreases. For example; it decreases linearly from 0.5687 to 0.4383 , from 0.7179 to 0.5705 , from 0.9998 to 0.9382 , from 0.7307 to 0.5825 , from 0.8773 to 0.7326 , from 0.866 to 07198 and from 0.976 to 0.8678 for waveguide length $150 \mathrm{~nm}, 180 \mathrm{~nm}$, and $210 \mathrm{~nm}$ respectively.

\subsection{Propagation loss}

The propagation loss efficiency is calculated using the equation (7), which depends on different parameters such as lattice spacing, input signal and the applied pressure. Using the values of the 
aforementioned parameters in the equation (7), the deviation of propagation loss efficiency with respect to the pressure is computed for all lengths as well as the input signal. The results are represented in figure 5 .

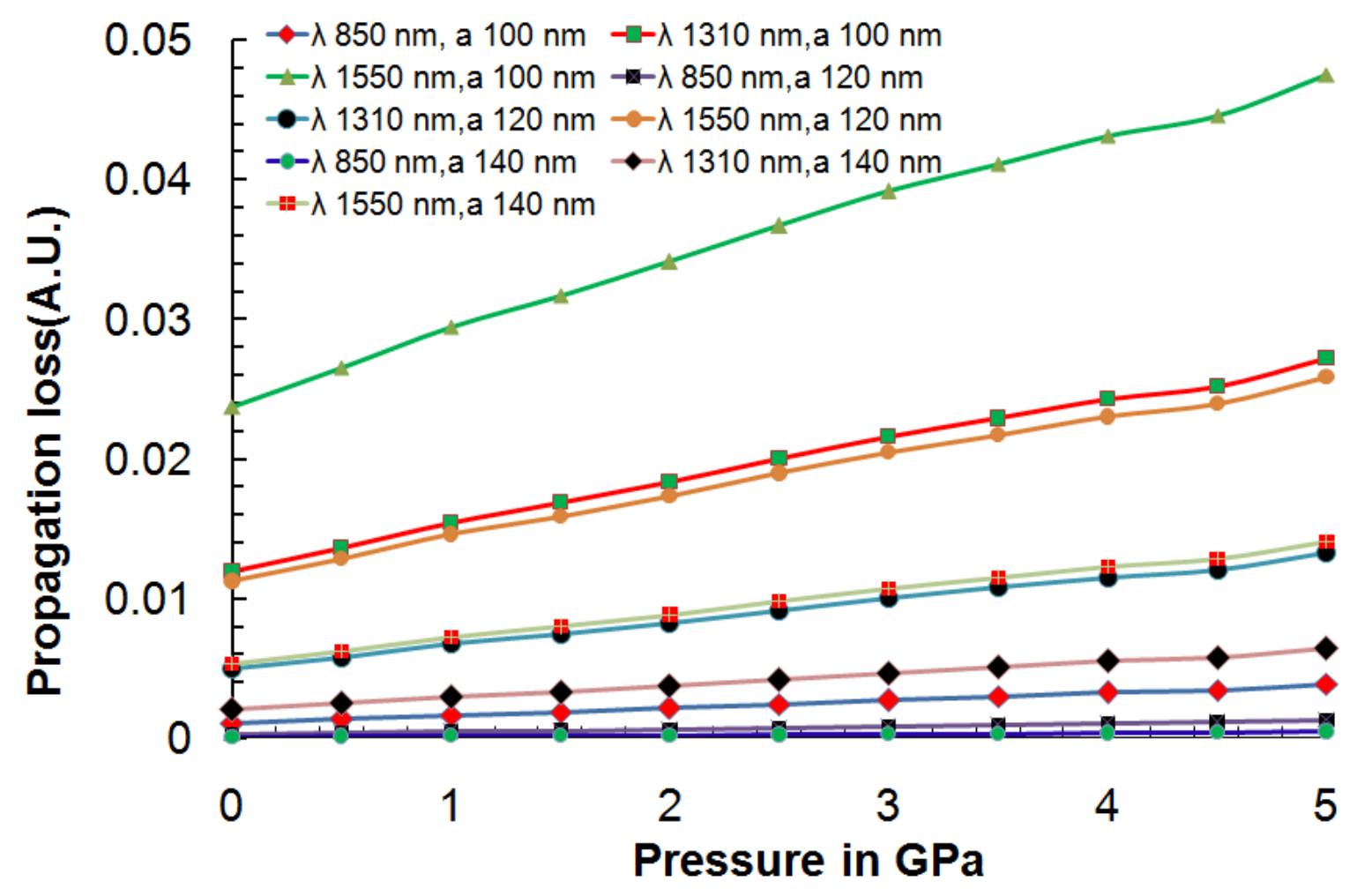

Figure 5: pressure vs propagation of InAs photonic waveguide

In this figure, propagation loss efficiency is taken along the $\mathrm{y}$ axis and pressure is selected in $\mathrm{x}$ axis. From this figure, it is found that it increases linearly corresponding to all wavelengths and waveguide lengths. For example; the propagation loss efficiency of waveguide length $150 \mathrm{~nm}$ increases from 0.001084 to $0.003864,0.01192$ to 0.027187 and 0.023667 to 0.04751 for input signals of $850 \mathrm{~nm}$, $1310 \mathrm{~nm}$ and $1550 \mathrm{~nm}$ respectively. Further, the propagation loss efficiency of waveguide length 180 $\mathrm{nm}$ increases from 0.000277 to $0.001272,0.004915$ to 0.01322 and 0.011193 to 0.025831 for input signals of $850 \mathrm{~nm}, 1310 \mathrm{~nm}$ and $1550 \mathrm{~nm}$ respectively. The propagation efficiency of waveguide length $210 \mathrm{~nm}$ increases from 0.0000706748 to $0.000418709,0.002026632$ to 0.006428522 and 0.005294078 to 0.014044308 for input signals of $850 \mathrm{~nm}, 1310 \mathrm{~nm}$ and $1550 \mathrm{~nm}$ respectively. It shows that propagation loss is very less compared to other loss.

\section{Calculation of transmitted intensity}

Ultimately, the transmitted intensity for all input signals would be computed with the help of equation (8-9). The output upshots relating to all selected wavelengths are represented in figure 6 . The pressure is taken $\mathrm{x}$ axes and transmitted intensity is taken y axes, which is shown in figure 6 . 


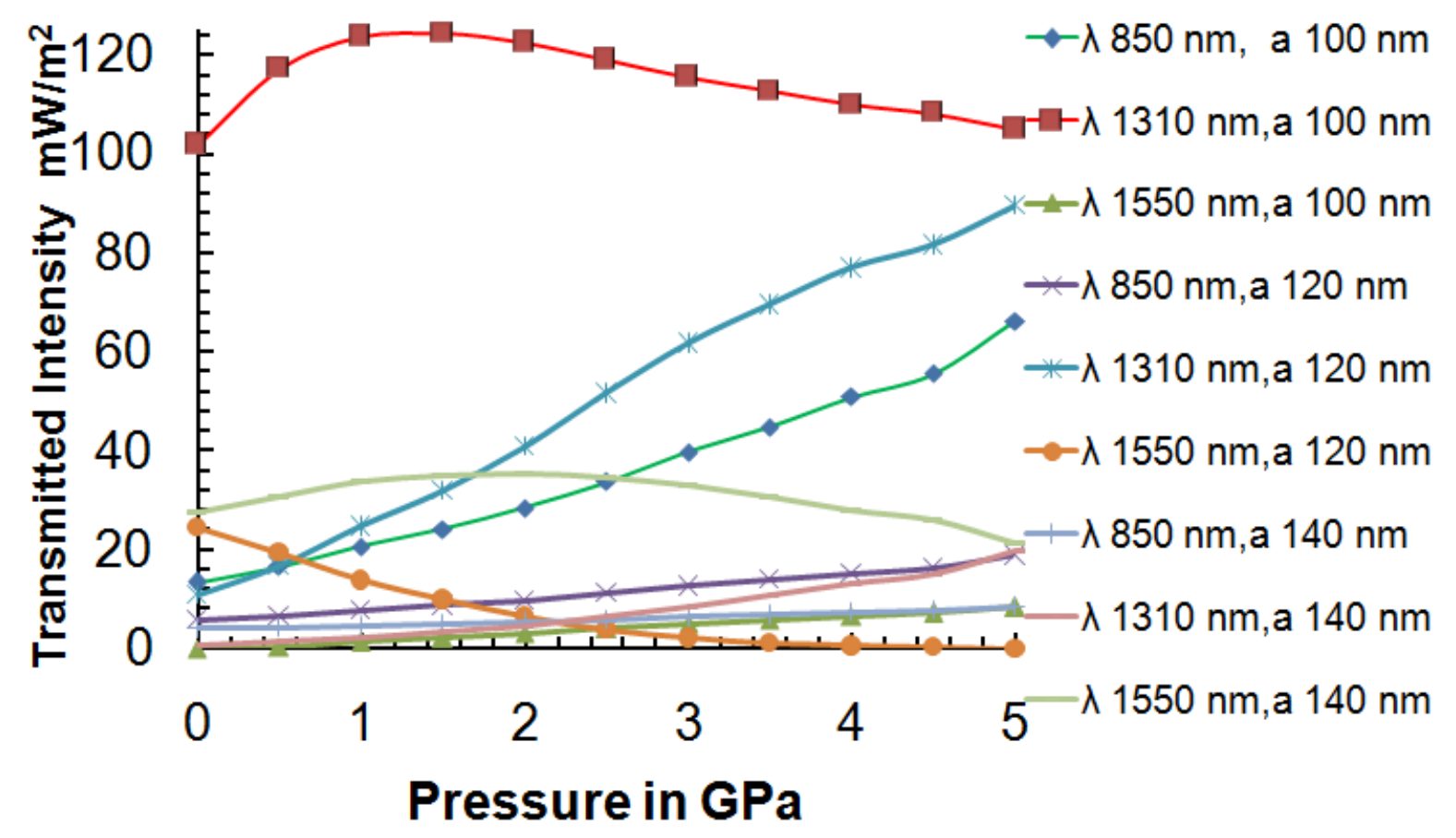

Figure 6: Pressure vs transmitted intensity of InAs photonic waveguide

In the figure 6; transmitted intensity in $\mathrm{mw} / \mathrm{m}^{2}$ is taken along vertical axis, where pressure in GPa is taken along the horizontal axis. In the figure 6; transmitted intensity varies randomly with respect to the pressure, which ranges from 0 to $5 \mathrm{GPa}$. For example; transmitted intensity for waveguide lengths $150 \mathrm{~nm}$ varies from $13.47558 \mathrm{~mW} / \mathrm{m}^{2}$ to $66.24082 \mathrm{~mW} / \mathrm{m}^{2}, 101.7669 \mathrm{~mW} / \mathrm{m}^{2}$ to $104.8819 \mathrm{~mW} / \mathrm{m}^{2}$ and $0.045712 \mathrm{~mW} / \mathrm{m}^{2}$ to $8.378594 \mathrm{~mW} / \mathrm{m}^{2}$ for input signal of $850 \mathrm{~nm}, 1310 \mathrm{~nm}$ and $1550 \mathrm{~nm}$ respectively. Similarly, transmitted intensities for the waveguide lengths $180 \mathrm{~nm}$ are 5.874614 $\mathrm{mW} / \mathrm{m}^{2}$ to $18.91186 \mathrm{~mW} / \mathrm{m}^{2}, 10.86182 \mathrm{~mW} / \mathrm{m}^{2}$ to $89.44023 \mathrm{~mW} / \mathrm{m}^{2}$ and $24.65279 \mathrm{~mW} / \mathrm{m}^{2}$ to $0.043074 \mathrm{~mW} / \mathrm{m}^{2}$ for input signal of $850 \mathrm{~nm}, 1310 \mathrm{~nm}$ and $1550 \mathrm{~nm}$ respectively. Moreover transmitted intensity of waveguide lengths $210 \mathrm{~nm}$ are $4.132978 \mathrm{~mW} / \mathrm{m}^{2}$ to $8.654502 \mathrm{~mW} / \mathrm{m}^{2}$, $0.755073 \mathrm{~mW} / \mathrm{m}^{2}$ to $19.76731 \mathrm{~mW} / \mathrm{m}^{2}$ and $27.6498 \mathrm{~mW} / \mathrm{m}^{2}$ to $21.45884 \mathrm{~mW} / \mathrm{m}^{2}$ for input signal of $850 \mathrm{~nm}, 1310 \mathrm{~nm}$ and $1550 \mathrm{~nm}$ respectively. From above analysis, it is observed that the amount of pressure on one dimensional indium arsenide photonic structure can be computed by knowing of output intensity.

\section{Conclusions}

In this research, the amount of pressure in the indium arsenide photonic materials is computed using one dimensional photonic structure. Here, different type of losses (diffraction loss, reflection loss, absorption loss, propagation loss, polarisation loss) are thoroughly analysed during the computation of transmitted intensities It is realised that amount of pressure in indium arsenide is determined by knowing the amount of transmitted intensities at the output end, which shows that InAs material is a good candidate for realisation of pressure sensor. 


\section{References}

[1] Vurgaftman,I., Meyer, J. R., Ram-Mohan, L. R.: Band parameters for III-V compound semiconductors and their alloys, J. Appl. Phys.,89,5815-5874(2001)

[2] Li, L., Jiang, Y., Ye, H., Yang, R. Q., Mishima, T. D., Santos, M. B., Johnson, M. B.: Low threshold InAs-based interband cascade lasers operating at high temperatures, Appl. Phys. Lett. 106, 251102(2015)

[3] Li, Y B, Stradling, R A, Knight, T, Birch, J R, Thomas, R H, Phillips, C C, Ferguson, I T:Infrared reflection and transmission of undoped and Si-doped InAs grown on GaAs by molecular beam epitaxy, Semiconductor Science and Technology, 8, 1-6(1993)

[4] Bennout M. et al,: Temperature dependence of optical properties of InAs quantum dots grown on GaAs(113)A and (115)A substrates, Journal of Nanoparticle Research 13,12(2011)

[5] Gaan, Susanta, Mondal, Subhra Rani, Sivaranjani, S., Mishra, C. S., Behera, S. K.,Palai, G.: Measurement of Sucrose Concentration Using Optical Metamaterial Structure Via FDTD Technique, IETE Research journal(2020)

[6] Mishra,C.S., Palai, G.: Simulation studies for reflected light of polymer waveguide for realization of temperature,Optik126,3656-3658(2015)

[7] Mishra, C.S., Palai, G.: Manipulating light with porous silicon for investigation of porosity using finite difference time domain method, Optik - International Journal for Light and Electron Optics, 127, 1195-1197(2016)

[8] Mishra, CS, Palai, G: Optical nonlinearity in germanium and silicon semiconductor vis-a-vis temperature and wavelengths for sensing application, Optik, 137, 37-44(2017).

[9] Lu, Tsan-Wen, Wu, Chia-Cheng, Lee, Po-Tsung: 1D photonic crystal strain sensors, ACS Photonics, 5, 2767-2772(2018).

[10] Yue, Youfeng, Gong, Jian Ping: Tunable one-dimensional photonic crystals from soft materials, Journal of Photochemistry and Photobiology C: Photochemistry Reviews Volume 23, 45-67(2015).

[11] Mishra, C.S., Palai,G.: Temperature and pressure effect on GaN waveguide at 428.71terahertz frequency for sensing application, Optik - International Journal for Light and Electron Optics, 126,4685-4687(2015)

[12] Sánchez, A., Porta A. V., Orozco, S.: Photonic band-gap and defect modes of a onedimensional photonic crystal under localized compression, Journal of Applied Physics 121, 173101 (2017); https://doi.org/10.1063/1.4982760

[13] Xu, Z.-Y., Zhang, R.-J., Gong Y.-L.:The principles of pressure sensors based on photonic crystal, Acta Physica Sinica -Chinese Edition- 53(3):724-727(2004) 
[14] Colodrero, S.,Ocaña, M., González-Elipe, A. R., Míguez, H.:Response of NanoparticleBased One-Dimensional Photonic Crystals to Ambient Vapor Pressure, Langmuir, 24, 16, 9135-9139(2008)

[15] Sabrinathan, J. et al: photonic crystal thin film micro- pressure sensors, journal of physics conference series 619, 012020(2015).

[16] Ben-Ali, Y., Elamri, F. Z., Ouariach, A., Falyouni, F.: A high sensitivity hydrostatic pressure and temperature based on a defective 1D photonic crystal, Journal of Electromagnetic Waves and Applications, Volume 34,1-21(2020).

[17] Chaves, Francis Segovia, Posada, Herbert Vinck: Dependence of the defect mode with temperature, pressure and angle of incidence in a 1D semiconductor-superconductor photonic crystal, Physica C: Superconductivity and its Applications Volume 553, Pages 1-7(2018).

[18] Herrera, Alan Y., Calero, J. M., Montenegro, N. Porras: Pressure, temperature, and thickness dependence of transmittance in a 1D superconductor-semiconductor photonic crystal, Journal of Applied Physics 123, 033101 (2018).

[19] Bouarissa, Nadir: Pressure dependence of refractive index, dielectric constants and optical phonon frequencies of indium arsenide, Optik - International Journal for Light and Electron Opticshttp://dx.doi.org/10.1016/j.ijleo.2017.03.082

[20] Dou, Yibo, Han, Jingbin, Wang, Tengli, Wei,Min, Evans, David G., Duan, Xue: Fabrication of $\mathrm{MMO}-\mathrm{TiO}_{2}$ one-dimensional photonic crystal and its application as a colorimetric sensor, J.Mater.Chem. 22, 14001(2012).

[21] Shen, Huaizhong, Wang, Zhanhua, Wu, Yuxin, Yang, Bai: One-dimensional photonic crystals: fabrication, responsiveness and emerging applications in 3D construction, RSC Adv., 6, 4505(2016).

[22] Liu, Zhicheng, Sun, Hao, Li, Yongzhuo, Zhang, Jianxing, Ning, C. Z.: Fabrication of 1D Photonic Crystal on a Single Erbium Chloride Silicate Nanowire and Microcavity Laser Design, conference 2015, San Jose, CA, USA https://doi.org/10.1364/CLEO_SI.2015.SW4I.2

[23] Ilinykh, V. A., Matyushkin, L. B.: Fabrication of one-dimensional photonic crystals by sol-gel method, 2016 confererence, St. Petersburg, Russia, 10.1109/EIConRusNW. 7448115(2016).

[24] Gutierrez, Cristian Felipe Ramirez, Hernandez, Harol David Martinez, Cabrera, Ivan Alonso Lujan García, Mario Enrique Rodriguez: Design, fabrication, and optical characterization of one-dimensional photonic crystals based on porous silicon assisted by in-situ photoacoustics, Scientific Reports volume 9, Article number: 14732 (2019).

[25] García,González, Colodrero, S., Míguez, H., Elipe, A. R. González: Single-step fabrication process of 1-D photonic crystals coupled to nanocolumnar $\mathrm{TiO}_{2}$ layers to improve DSC efficiency, Optics Express, Vol. 23, A1642( 2015). 
Figures

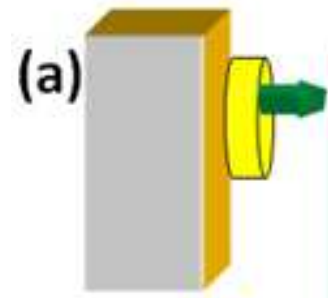

$850,1310,1550 \mathrm{~nm}$ Source

(b)

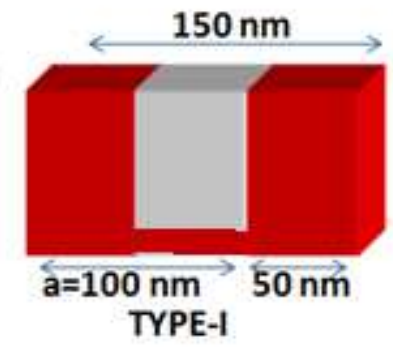

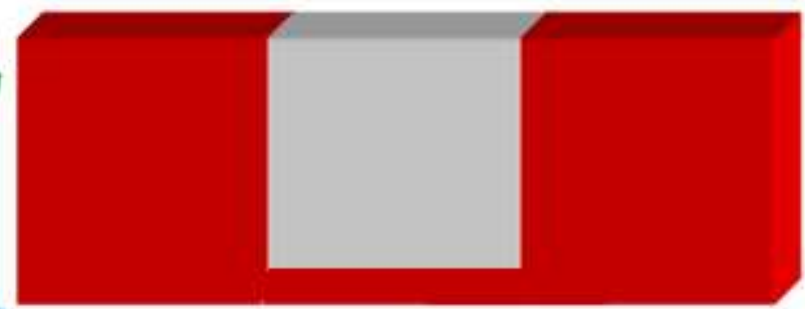

InAs

Air

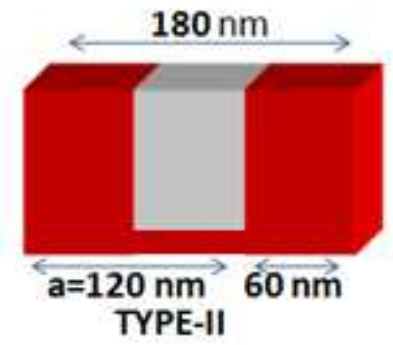

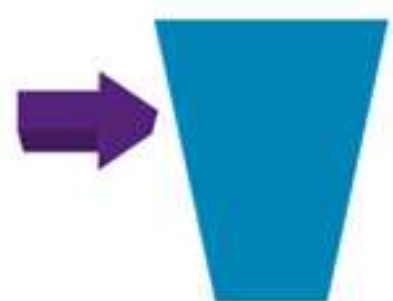

\section{InAs Photo detector}

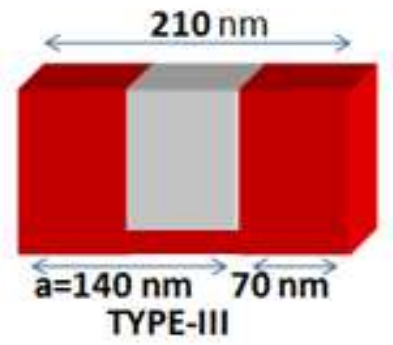

Figure 1

(a) proposed InAs 1-D waveguide structure b) 1-D InAs based photonic structure with different waveguide lengths.

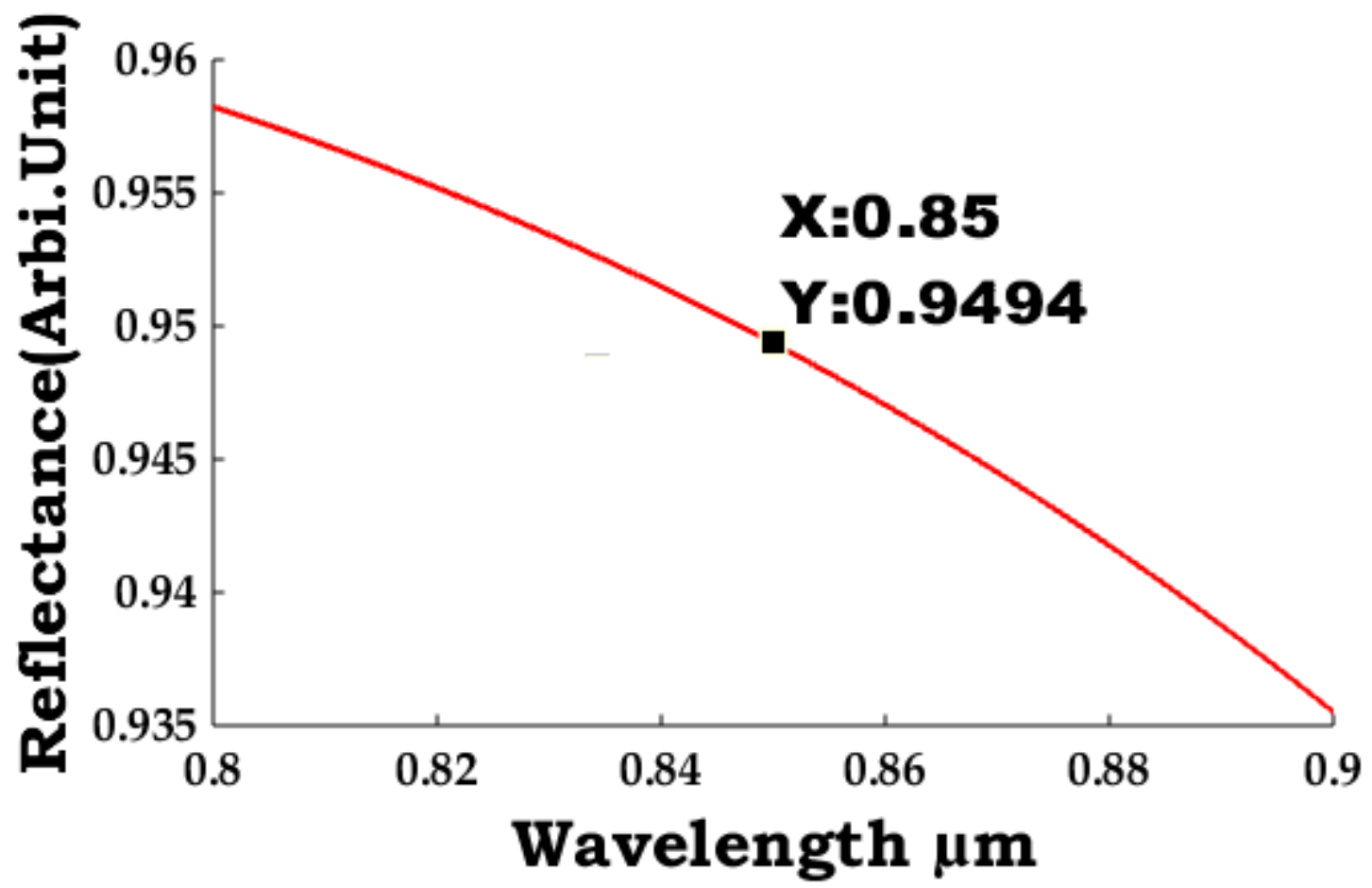

Figure 2 
reflectance curve InAs of waveguide length $150 \mathrm{~nm}$ at input signal $850 \mathrm{~nm}$

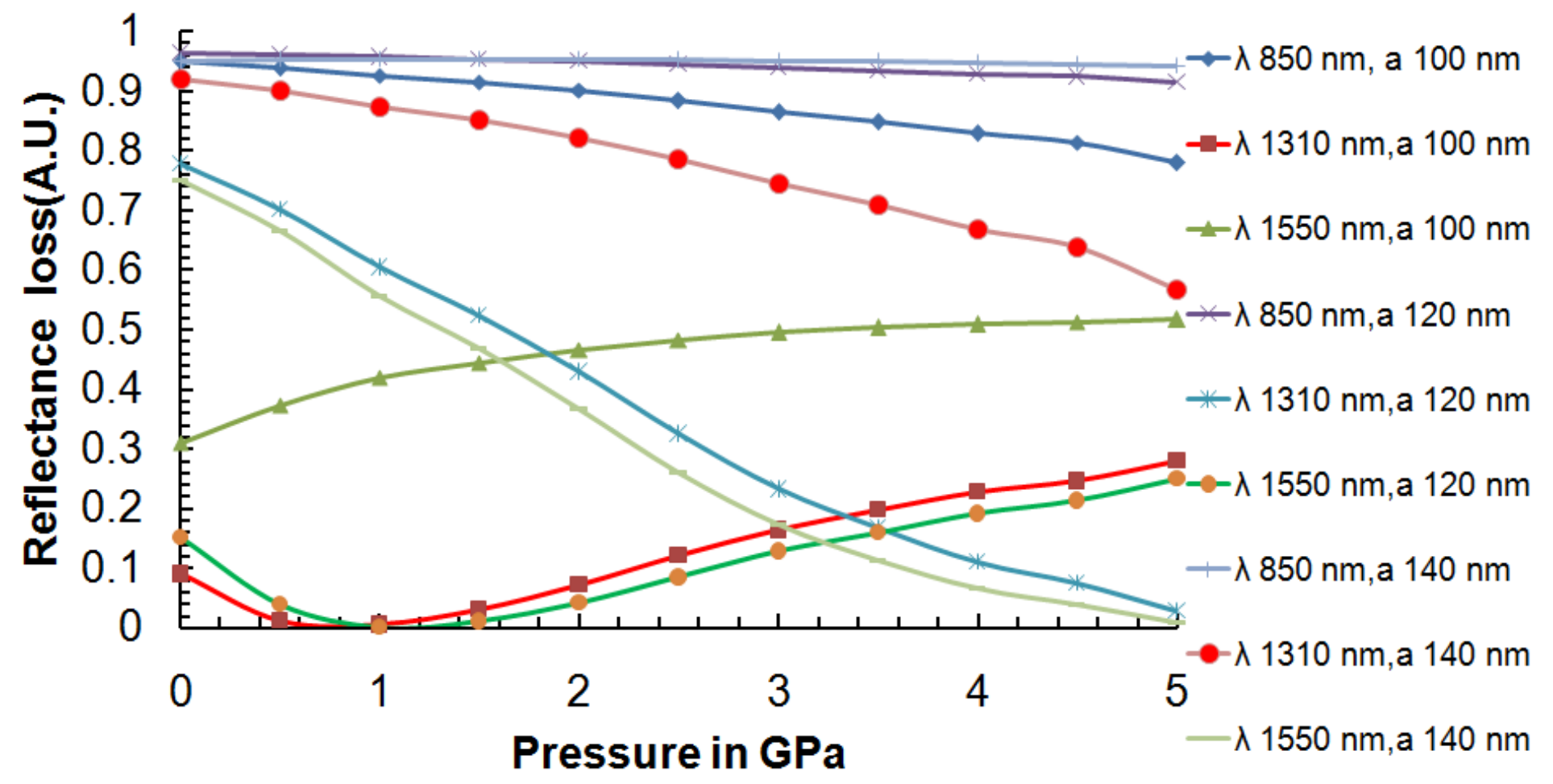

Figure 3

Reflectance graph of InAs waveguide length $150 \mathrm{~nm}$ at input signal $850 \mathrm{~nm}$

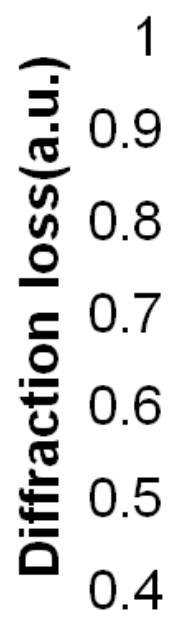

E

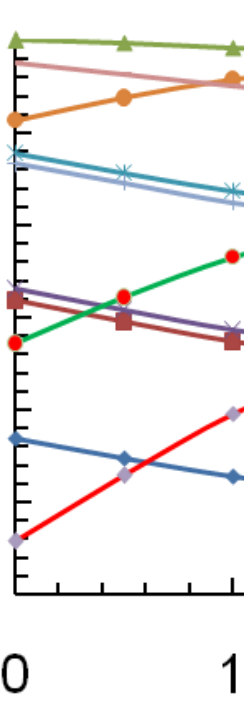

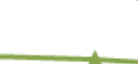
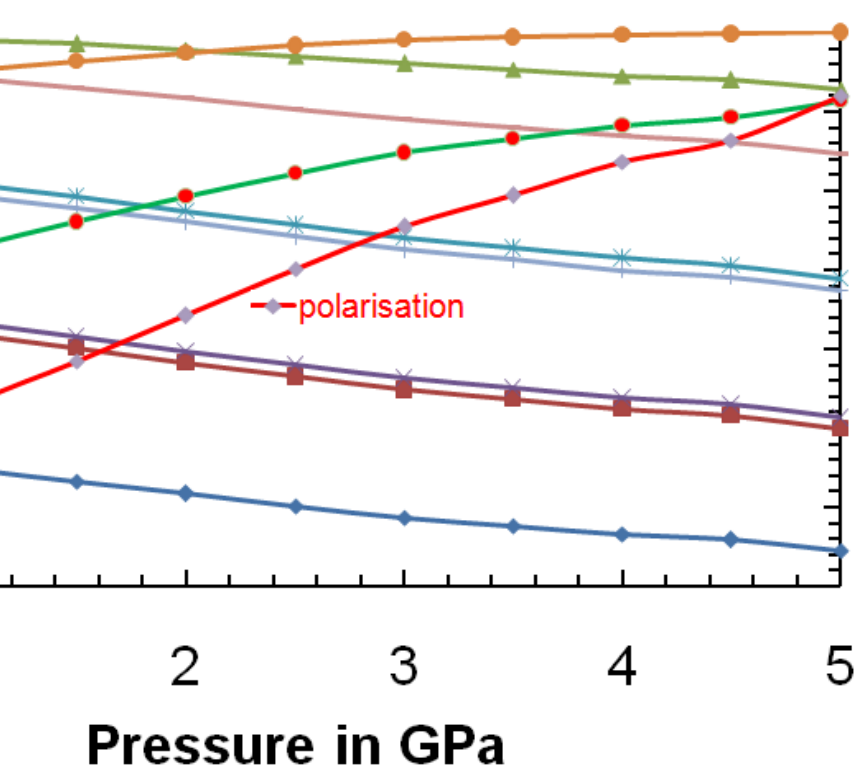

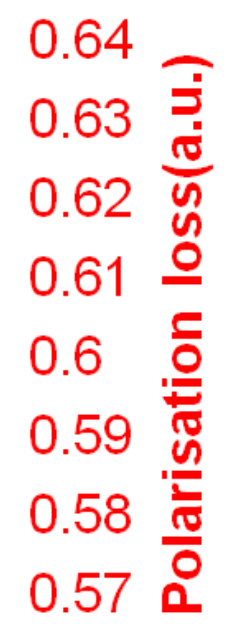

5 $\rightarrow \lambda 1550 \mathrm{~nm}, \mathrm{a} 100 \mathrm{~nm}$ $-\lambda 1310 \mathrm{~nm}, \mathrm{a} 100 \mathrm{~nm}$ $\leftarrow \lambda 850 \mathrm{~nm}, \mathrm{a} 100 \mathrm{~nm}$ $* \lambda 1550$ nm,a $120 \mathrm{~nm}$ * $\lambda 1310 \mathrm{~nm}, \mathrm{a} 120 \mathrm{~nm}$ $\rightarrow \lambda 850 \mathrm{~nm}, \mathrm{a} 120 \mathrm{~nm}$ $+\lambda 1550 \mathrm{~nm}, \mathrm{a} 140 \mathrm{~nm}$ $-\lambda 1310 \mathrm{~nm}, \mathrm{a} 140 \mathrm{~nm}$

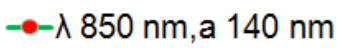

Figure 4

polarisation and diffraction vs pressure 1-D InAs photonic waveguide 


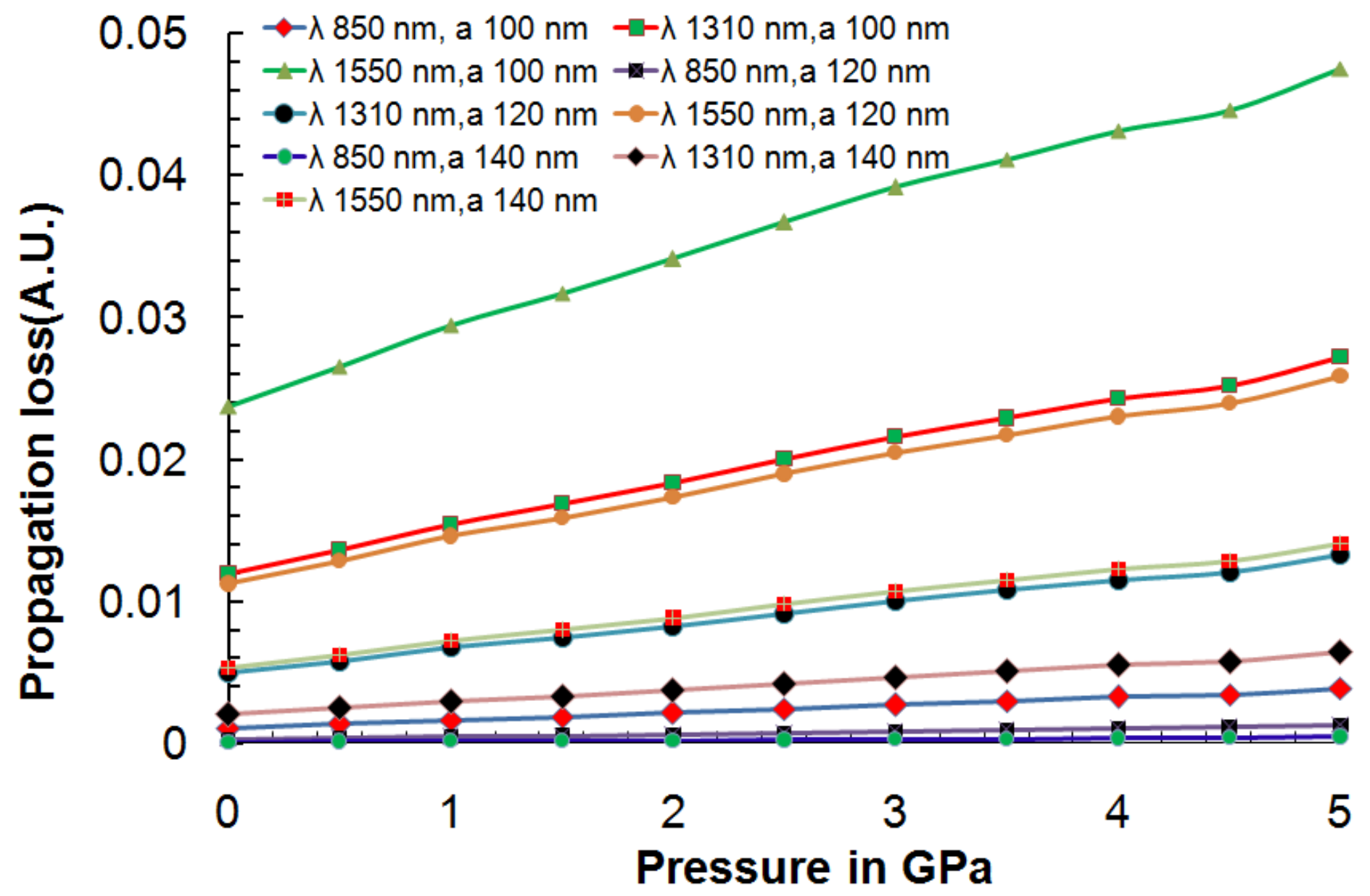

Figure 5

pressure vs propagation of InAs photonic waveguide 


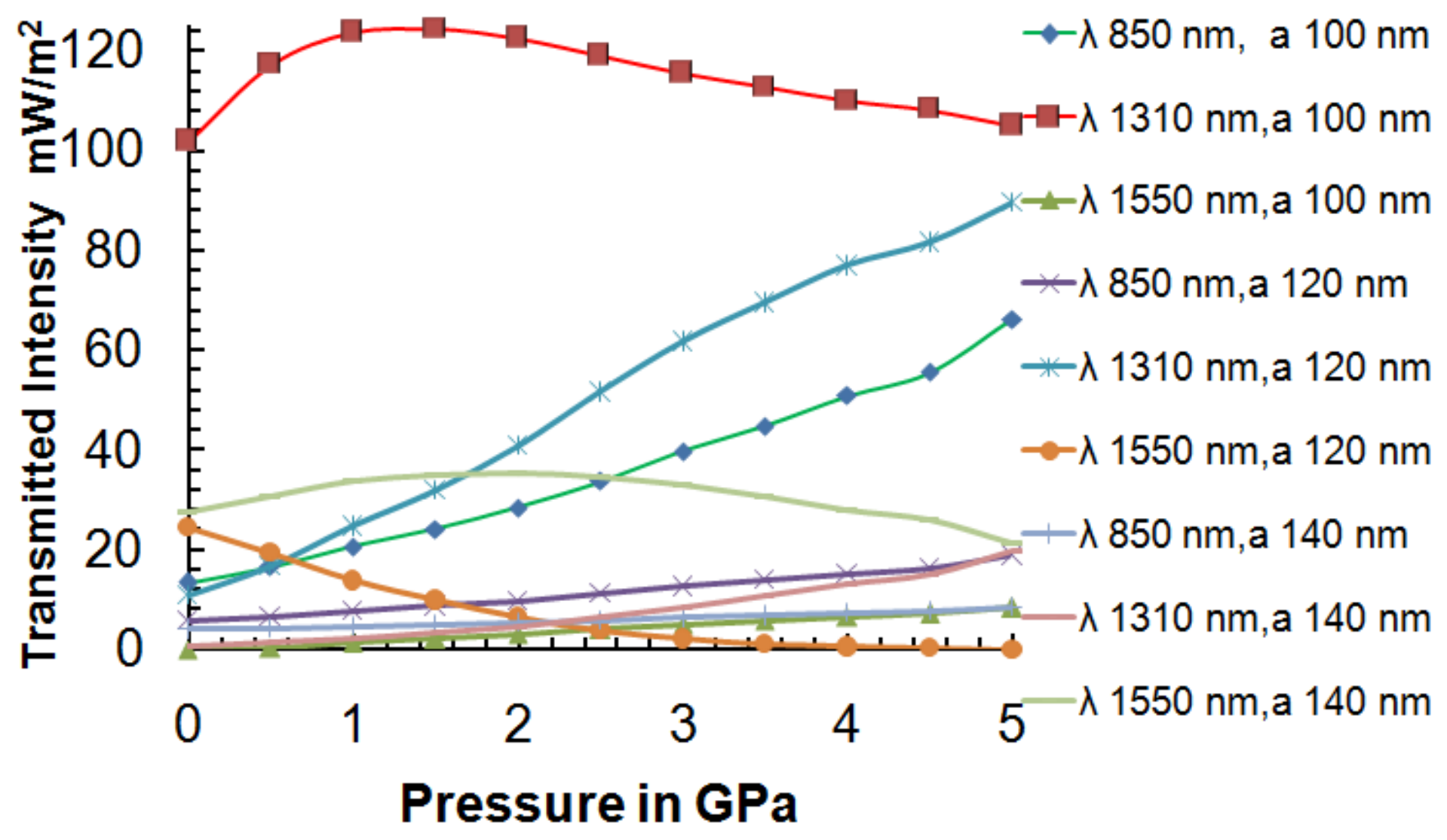

Figure 6

Pressure vs transmitted intensity of InAs photonic waveguide 